operation between the technical faculties of our universities and the industries concerned, in America such co-operation is already an established fact, and reports such as the present one show evidence of its value.

This bulletin is merely a preliminary one, presenting a complete and concise account of what is known up to the present on the subject of subsidences due to mining operations, and the authors have done their work in a most thorough and painstaking fashion, and have missed very little of the published information on the subject, in spite of the difficulty of bringing it together from the large number of scattered records through which it is disseminated. It need scarcely be said that the subject is one of the greatest importance in this country, where so many of our most densely populated industrial centres are situated upon the coalfields themselves. The problem whether large masses of coal should be left in the form of supporting pillars, and thus be permanently lost to the nation, or to what extent it is advisable to remove them, with the risk, or even with the certainty, of causing a certain amount of surface damage, is obviously one of first-rate importance, especially at times like the present, when the proper conservation and full utilisation of our natural resources demand our utmost attention.

Messrs. Young and Stock have contented themselves with summarising the theories on subsidence promulgated by various writers, notably the Belgian, French, Prussian, and Austrian theories; there cannot really be said to be any British or American theories, although various British engineers have proposed formulas, notablv for determining the angle of "draw," and the size of the coal pillars that must be left in order adequately to protect any given area of surface; the wide divergence of these various formulas is well shown by a diagram, reproduced from a paper by Prof. George Knox, which shows that some of these give results ten times as great as those given by others.

The introductory notice to the present bulletin suggests that the Illinois authorities propose to study the problem in a systematic fashion, by taking careful levels across selected groups of mines at regular intervals, and simultaneously noting the conditions of the underground workings, such observations to be continued for a number of years, when it may be hoped that it will be found possible to correlate surface subsidences and underground workings, and thus to obtain data that will enable the conditions of maximum economy to be determined. This is a subject that might with the greatest advantage be taken up on similar lines by one or other of the committees formed to deal with industrial research in this country.

H. L.

\section{FURTHER STUDIES IN PLANT GENETICS.}

THE September number of the American Naturalist (vol. 1., No. 597) is devoted to studies of inheritance in plants. Dr. H. H. Bartlett writes on "The Status of the Mutation Theory, with especial reference to CEnothera." $\mathrm{He}$ "finds incredible the arguments that have been brought forward in favour of the idea that mutation and Mendelian segregation are the same." Nevertheless, it still remains to be decided "whether or not mutation is always, or ever, conditioned by previous hybridisation." Dr. O. E. White describes some researches in continuation of Mendel's original subject-the inheritance of cotyledon colour in Pisum. Alleged differences between the colour of segregated seeds of the $\mathrm{F}_{2}$ generation and those of the original parents are attributed to environmental changes: yellow-cotyledon varieties may produce green seeds because of immaturity, absence of sunlight, or excess of moisture, while green-cotyledon varieties may fade to yellow or yellowish-green through excess of sunlight. In one variety-"Goldkönig" - with yellow cotyledons, the yellow colour is, contrary to the usual rule, recessive to green. This form "may be regarded as lacking both the factor for causing green pigment and the factor for causing that pigment to fade on the maturity of the seed." When "Goldkönig" is crossed with yellow-seeded varieties in which yellowness is dominant, the $F_{1}$ generation are all yellow-seeded, and the $\mathrm{F}_{2}$ generation are segregated in the proportion of three green to thirteen $(9+3+1)$ yellow.

"Inheritance of Sex in the Grape" is discussed by W. D. Valleau. Wild vines bear flowers which are functionally either male or female, but the carpels or pistils are respectively present in a reduced condition; the plants are thus transitional between the hermaphrodite and the dicecious form. Functional hermaphrodites, however, appear in cultivation. Breeding experiments suggest that "both the staminate and functionally pistillate vines carry the determiners for femaleness and maleness, respectively, partially suppressed."

The Journal of Genetics for September (vol. vi., No. I) is completely occupied by Prof. A. H. Trow's analysis of form and inheritance in the common groundsel (Senecio vulgaris). In a long paper he discusses the number of nodes and their distribution along the main axis in this species and its segregates. Dividing the families of plants studied into "low" (9-16 nodes), "medium" (18-26 nodes), and "high" (30-3I nodes), he finds that medium characters are dominant to both low and high, and infers, therefore, the existence of two pairs of alternative determinants. However, from the cross "medium" $\times$ "high" there emerge families with from $36-39$ nodes, forming a "very high" group; this "segregates out from "high" as a recessive." From the cross "low" $\times$ " high" other anomalous results were obtained, and the author foresees many years' work before definite conclusions can be reached. In a short paper Prof. Trow discusses the inheritance of "albinism" in groundsel; he finds that in some forms the expected ratio of green to white plants as $I_{5}$ to $I$ is obtained in the $F_{2}$ generation; in others it is unaccountably departed from.

\section{THE ORGANISATION AND DEVELOPMENT OF CHEMICAL INDUSTRY AND RE- SEARCH. ${ }^{2}$}

SOUTH AFRICA is a country which has hitherto $S$ existed, and still does at the present moment exist, on its rich stock of raw materials. Its exports, in addition to the raw products of agriculture, are chiefly metals, crude and unrefined, and diamonds uncut. The chief chemical industry is the preparation of raw gold bullion from the quartzitic ore of the Transvaal. This is carried out in three operations - the first being fine pulverisation by mechanical means; the second, amalgamation with mercury: and the third, solution of the unamalgamated gold still remaining by means of sodium cyanide solution, followed by reprecipitation with excess of zinc shavings and final treatment of the metal, so as to get rid of as much of the base metal present as possible before pouring into commercial bars. The major portion of the plant necessary for these operations consists of iron and steel, and the raw materials for their manufacture exist in comparative aburdance in the Transvaal. A thorough and scientificilly com-

1 From the presidential address delivered to Secrion B-Chemistry,
Geolngy, Metallurgy, Mineralogy, and Geography-of the South African Seolngy, Metallurgy, Mineralogv, and Geography-of the South African Association for the Advancement of Science at the Maritzburg meeting,
July 4, 19 6, by Prof. J. A. Wilkinson. NO. 247I, VOL. 99] 